University of Massachusetts Amherst

ScholarWorks@UMass Amherst

Travel and Tourism Research Association: Advancing Tourism Research Globally

\title{
Understanding Precedents for Frontline Employee Turnover in Luxury Hotels: Emotional Intelligence as a Unifying Factor
}

Chenchen Huang

State University of New York Buffalo State

Kai Wu

Dongbei University of Finance and Economics

Follow this and additional works at: https://scholarworks.umass.edu/ttra

Huang, Chenchen and Wu, Kai, "Understanding Precedents for Frontline Employee Turnover in Luxury Hotels: Emotional Intelligence as a Unifying Factor" (2015). Travel and Tourism Research Association: Advancing Tourism Research Globally. 25.

https://scholarworks.umass.edu/ttra/ttra2015/Academic_Papers_Visual/25

This Event is brought to you for free and open access by ScholarWorks@UMass Amherst. It has been accepted for inclusion in Travel and Tourism Research Association: Advancing Tourism Research Globally by an authorized administrator of ScholarWorks@UMass Amherst. For more information, please contact scholarworks@library.umass.edu. 
Understanding Precedents for Frontline Employee Turnover in Luxury Hotels: Emotional Intelligence as a Unifying Factor

Introduction

Insufficient turnover research in the hotel literature fails to serve the needs of an industry that is long plagued by employee turnover. Empirical studies suggest that annual employee turnover rate in the hotel industry ranges from $60 \%$ to $300 \%$ (Cheng, Yang, Wan, \& Chu, 2013).The magnitude of the turnover issue is exemplified by its financial costs. In addition, understanding precedents for employee turnover is especially crucial for the management of luxury hotels because of employee turnover related service quality issues and reduced employee productivity (Mohsin, Lengler, \& Kumar, 2013).

Published research on precedents for employee turnover in hotels neglects two important factors: emotional intelligence and pay satisfaction. Emotional intelligence potentially affects the employees' evaluation and emotional reactions towards burnout, compensation, and organizational support. The indirect impact of emotional intelligence is likely significant on turnover intention. Although the management literature (e.g., Vandenberghe \& Tremblay, 2008) identifies pay satisfaction as an important predictor to employee turnover, it has yet to be tested in a hotel context.

This study was conducted to: 1) investigate the direct impacts of emotional intelligence, burnout, pay satisfaction, and organizational support on turnover intention among frontline employees in luxury hotels; and 2) investigate the indirect and total impacts of emotional intelligence on turnover intention among frontline employees in luxury hotels.

Related literature

Psychologists originally identified and defined job burnout as a prolonged condition of emotional exhaustion, depersonalization and diminished personal achievement due to an individual's job (Maslach \& Jackson, 1981). Extended and severe job burnout has significant impacts on employees, such as insomnia, decreased life satisfaction, and other psychical and psychological problems (Haye \& Weathington, 2007; Peterson, 2000; Pines and Aronson, 1988). From the management's perspective, a high level of job burnout could lead to employee dissatisfaction and high employee turnover rates (Shen \& Huang, 2012; Zellars, Perrewé, \& Hochwarter, 2000).

Based on the social exchange perspective, organizational support theory is often utilized to explain employee-organization relationships. Perceived Organizational Support (POS) can be defined as "global beliefs concerning the extent to which the organization values their contributions and cares about their well-being (Eisenberger, Huntington, Hutchison, \& Sowa, 1986, p. 501)." Employees with high POS are likely to respond positively to the organization; while low POS has been found to negatively impact job performance, job satisfaction, and organizational commitment (Loi, Ngo, \& Foley, 2006), and to increase intention to leave (Allen, Shore, \& Griffeth, 2003).

The economic exchange between employees and organization is also an important perspective of the employee-organization relationship. Researchers (e.g., Ambrose \& Schminke, 2003) generally separate the economic exchange from the social exchange. In organizational research, the economic exchange as perceived by employees is often referred to as distributive justice. When an organization distributes economic compensation to its employees, employees' pay satisfaction reflects their perceptions of distributive justice. Both equity and expectancy are important components of pay satisfaction. Distributive justice has a significant impact on organizational commitment (e.g. Moideenkutty et al., 2001). In previous studies, pay satisfaction 
has been found as an important predictor to employee turnover in various industries (Carraher, 2011).

A stream of research on emotion work aims to identify "psychological resources" (Hobfoll, 2011) that mitigate the negative effects of emotion work. Terms such as emotional competence and emotional intelligence have been used to capture those individual psychological recourses and to indicate and measure individuals' capacity of handling affective information efficiently (Grandey, 2000; Saarni, 1999; Salovey \& Mayer, 1989).Emotional Intelligence can be defined as "the ability to perceive accurately, appraise, and express emotion; the ability to access and/or generate feelings when they facilitate thought; the ability to understand emotion and emotional knowledge; and the ability to regulate emotions to promote emotional and intellectual growth." (Mayer \& Salovey,1997, p. 10). Mayer \& Salovey (1997) further conceptualized EI in four dimensions: 1) self-emotion appraisal, 2) others' emotion appraisal, 3) regulation of emotion, and 4) use of emotion. Through the mediating effects of job burnout, perceived organizational support, and pay satisfaction, emotional intelligence might have negative indirect impacts on turnover intention and negative total impact on turnover intention.

Theoretical model

Figure 1: Theoretical model

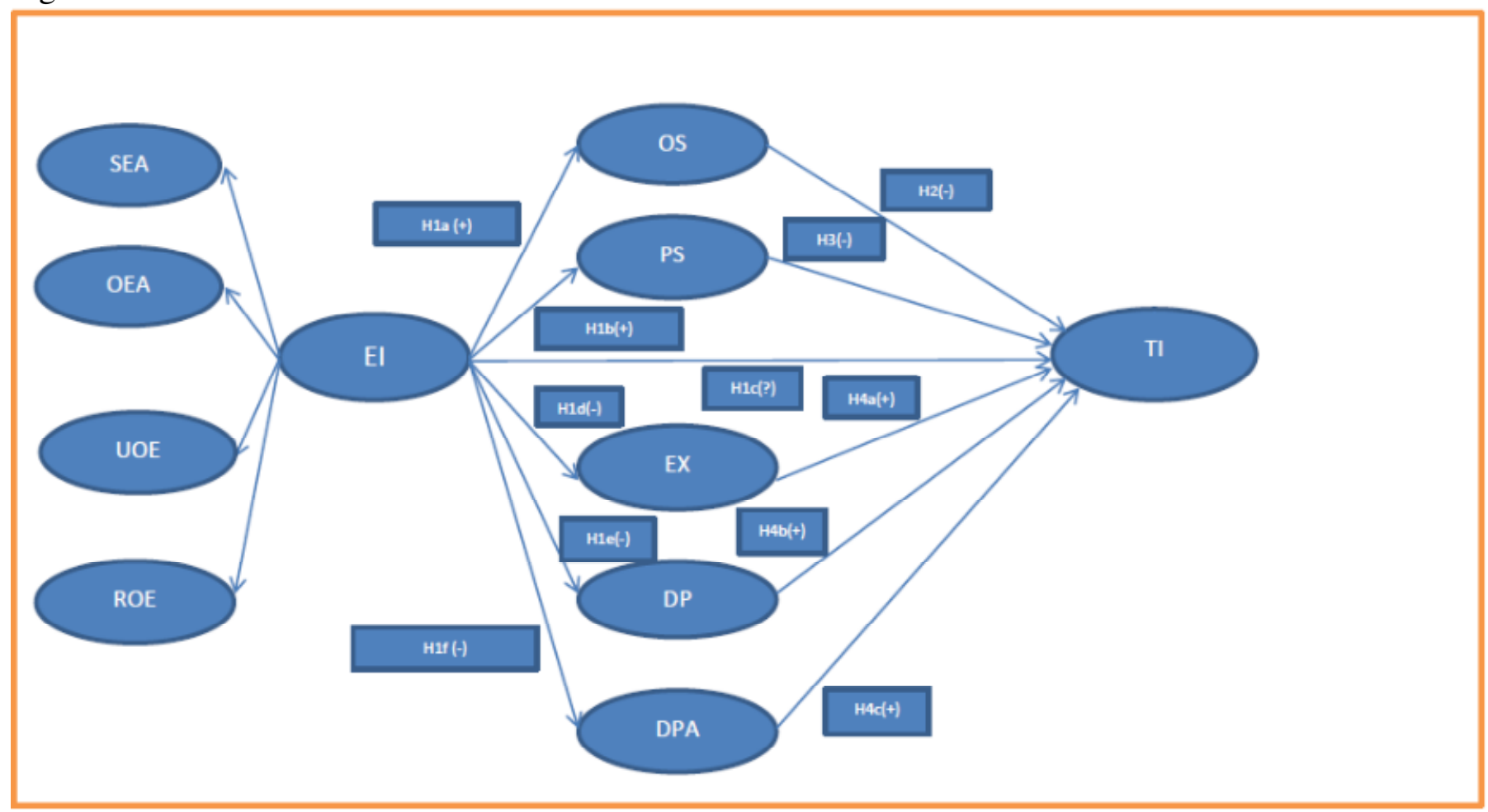

SEA: Self Emotional Awareness; OEA: Other's Emotional Awareness; ROE: Regulation of Emotion; UOE: Use of Emotion; EI: Emotional Intelligence; OS: Organizational Support; PS: Pay Satisfaction; EX: Emotional Exhaustion; DP: Depersonalization; DPA: Diminished Personal Accomplishment; TI: Turnover Intention.

$\underline{\text { Sample and Data collection }}$

This study collected information from employees at eight five-star hotels in Dalian, China from April 2014 to May 2014 through a questionnaire. Among the eight hotels, five are joint-ventures with an international brand affiliation, while three are domestic Chinese brands. A total of 1204 completed questionnaires were collected. Only employees who have direct 
customer service responsibilities at front-line departments are included in this study. As a result, the total usable sample size for this study is 438 .

Data Analysis

The measurement model shows that the proposed model fits the data well. Based on structural equation modeling, the results of the estimated model are presented in figure 2 with standardized path coefficients.

Figure 2: Structural equation modeling with standardized estimates

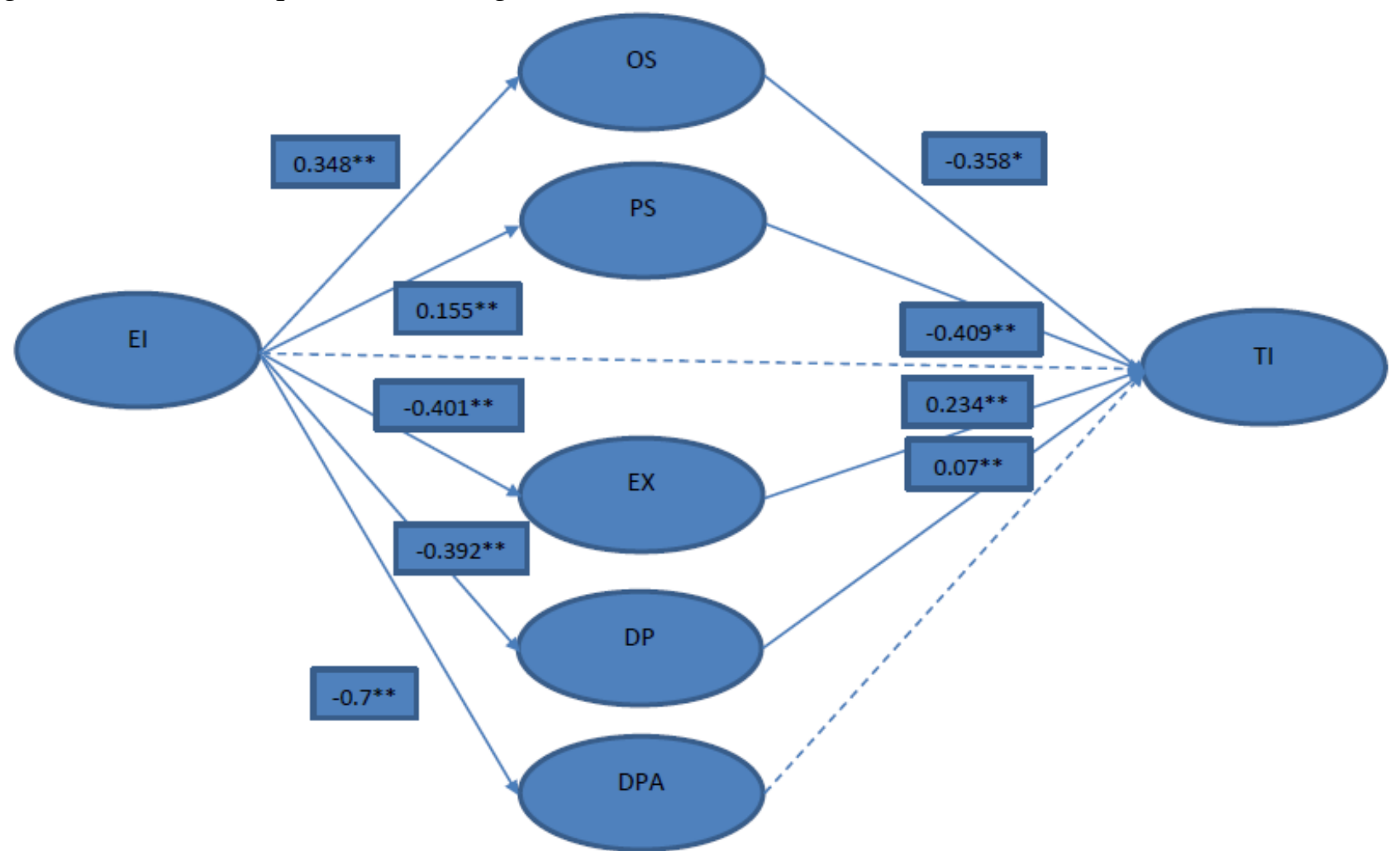

Notes: Solid lines indicate significant paths. Dotted lines indicate non-significant paths. * $\mathrm{P}$ value $<0.05 ; * * \mathrm{P}$ value $<0.01$

In addition to the direct effects presented in Figure 2, total effect of EI (Emotional Intelligent) on TI (Turnover Intention) was also analyzed. In this analysis, POS, PS, EX, DP, and DPA mediate between EI and TI. Baron and Kenny (1986) was the generally accepted standard for measuring mediation effects for decades. However, Zhao, Lynch, and Chen (2010) suggest that bootstrap tests provide significantly improved rigor and power in establishing mediation and supplement the original Baron and Kenny (1986) method substantially. The bootstrap module in AMOS provides the option to test the significance of indirect effect, direct effect and the total effect. Table 4 lists the coefficient and significance (two-tail significance generated by the biascorrected percentile method) of the indirect effect, direct effect, and total effect of EI on TI. Table 1: Indirect, direct and total effect of EI on TI

\begin{tabular}{llll}
\hline & Direct effect & Indirect effect & Total effect \\
\hline Coefficient & -0.064 & -0.537 & -0.196 \\
Significance level & 0.174 & 0.001 & 0.008 \\
\hline
\end{tabular}

$\underline{\text { Discussions }}$

Consistent with the literature, POS has a significantly negative impact on turnover intention. Employees with higher POS are less likely to leave the hotel. In the employee-hotel 
social exchange, employees might feel obligated to "return the favor" if they receive adequate support from the hotel. Pay satisfaction manifests employees' satisfaction with the payment they receive from the economic exchange between the hotel and employees. Unsurprisingly, pay satisfaction significantly affects turnover intention. Employees who are more satisfied with their pay are less likely to turnover. The literature on emotional labor suggests that employees with higher level of job burnout are more likely to turnover. Data from this study show that two dimensions of job burnout, emotional exhaustion and depersonalization, have significantly positive impacts on employee turnover intention, while diminished personal accomplishment does not have a significant impact. It is possible that employees who suffered from job related emotional stress are likely candidates for turnover.

POS and pay satisfaction are organization related factors that predict employee turnover intention. Job burnout is more related to individual characteristics of employees. The current hotel management literature lacks efforts to unify organizational factors and individual factors as precedents for turnover. If identified precedents remain fragmented and unorganized, it is difficult for hotel managers to implement managerial procedures to address those factors. Data from this study suggests that EI could be a unifying factor in understanding organizational factors and individual factors in affecting employee turnover intention.

Organizational factors are perceived and interpreted by individual employees. Consequently, employees' EI plays an important role in shaping employees' perceptions of organizational support and payment received from the hotel. Data from this study shows that EI has a positive impact on POS and pay satisfaction. With the same level of organizational support and pay, employees with higher EI will perceive them more positively. Through the mediating effect of POS and pay satisfaction, EI has a negative impact on turnover intention.

Job burnout reflects a negative mental and emotional status resulted from prolonged stresses at work. EI represents emotional resources possessed by individuals. Similar work related emotional issues, resulting from interactions with customers and coworkers, might have different effects on employees with various EI. For the same emotion work, employees with higher EI might have less job burnout symptoms. Data from this study indicate that EI has negative impacts on the three dimensions of job burnout. Through the mediation of job burnout, EI has a negative impact on turnover intention.

$\underline{\text { Implications }}$

Clearly EI is an underlining factor that could unify the factors predicting employee turnover. For luxury hotel managers, this provides an important new angle for dealing with the issue of high turnover among frontline employees. Hotel managers have limited room in further improving organizational support, increasing pay, and reducing factors that trigger job burnout directly in the short run. However, managers should put higher EI as one of the recruitment criteria (Ashkanansy and Daus 2002). With easily available measurement tools for EI, hotel managers can find candidates with high EI and reduce employee turnover from the beginning of the employee-organization relationship.

In addition, helping employees to improve on their EI deserves more attention from the management. Employees' EI can be trained and developed (Bardzil and Slaski 2003; Goleman 2000).Trainings in EI skills will help employees internalize the emotional demands and adopt "deep acting" strategies. In addition, management can strive to provide an emotionally healthy workplace climate for frontline employees and create group programs that encourage astute use of emotions (Jung and Yoon 2012). If the management can provide opportunities for frontline employees to improve their EI, employee turnover will decrease as a result. 


\section{References}

Ambrose, M. L., \& Schminke, M. (2003). Organization structure as a moderator of the relationship between procedural justice, interactional justice, perceived organizational support, and supervisory trust. Journal of Applied Psychology, 88, 295-305.

Allen, D. G., Shore, L. M., \& Griffeth, R. W. (2003). The role of perceived organizational support and supportive human resource practices in the turnover process. Journal of Management, 29, 99-118.

Bardzil, P., \& Slaski, M. (2003). Emotional intelligence: fundamental competencies for enhanced service provision. Managing Service Quality, 13(2), 97-104.

Baron, R. M., \& Kenny, D. A. (1986), Moderator-Mediator variables distinction in social psychological research: Conceptual, strategic, and statistical considerations. Journal of Personality and Social Psychology, 51(6), 1173-82.

Carraher, S. M., (2011) Turnover prediction using attitudes towards benefits, pay, and pay satisfaction among employees and entrepreneurs in Estonia, Latvia, and Lithuania. Baltic Journal of Management, 6(1), pp.25 - 52.

Cheng, P. Y., Yang, J. T., Wan, C. S., \& Chu, M. C. (2013). Ethical contexts and employee job responses in the hotel industry: The roles of work values and perceived organizational support. International Journal of Hospitality Management, 34, 108-115.

Eisenberger, R., Huntington, R., Hutchison, S., \& Sowa, D. (1986). Perceived organizational support. Journal of Applied Psychology, 71, 500-507.

Goleman, D. 2000. Leadership that gets results. Harvard business review 78(2): 78-93.

Grandey, A. (2000). Emotion regulation in the workplace: A new way to conceptualize emotional labor. Journal of Occupational Health Psychology, 5, 95-110.

Haye, C. T., \& Weathington, B. L. (2007). Optimism, stress, life satisfaction, and job burnout in restaurant manager. The Journal of Psychology, 141(6), 565-579.

Hobfoll, S. E. (2001). The influence of culture, community, and the nested-self in the stress process: Advancing conservation of resources theory. Applied Psychology: An International Review, 50, 337-421.

Loi, R., Hang-Yue, N., \& Foley, S. (2006). Linking employees' justice perceptions to organizational commitment and intention to leave: The mediating role of perceived organizational support. Journal of Occupational and Organizational Psychology, 79(1), 101-120.

Maslach, C., \& Jackson, S.E. (1981). The measurement of experienced burnout. Journal of Occupational Behavior, 2, 99-113.

Mayer, J.D., \& Salovey, P., 1997. What is emotional intelligence? In: Salovey, P., Sluyter, D.J. (Eds.), Emotional Development and Emotional Intelligence: Educational Implications. Basic Books: New York, pp. 3-34.

Mohsin, A., Lengler, J., \& Kumar, B. (2013). Exploring the antecedents of intentions to leave the job: The case of luxury hotel staff. International Journal of Hospitality Management, 35, 48-58.

Moideenkutty, U., Blau, G., Kumar, R., \& Nalakath, A. (2001). Perceived organizational support as a mediator of the relationship of perceived situational factors to affective organizational commitment. Applied Psychology: An International Review, 50, 615634.

Peterson, C. (2000). The future of optimism. American Psychologist, 55, 44-55. 
Pines, A., \& E. Aronson. (1988). Career Burnout: Causes and Cures. New York: The Free Press, pp. 56.

Saarni, C. (1999). The Development of Emotional Competence. Guilford Press.

Salovey, P., \& Mayer, J. D. (1989). Emotional intelligence. Imagination, cognition and personality, 9(3), 185-211.

Shen, H., \& Huang, C. (2012) Domestic migrant workers in China's hotel industry: An exploratory study of their life satisfaction and job burnout. International Journal of Hospitality Management, 31 (4), 1283-1291.

Vandenberghe, C., \& Tremblay, M. (2008). The role of pay satisfaction and organizational commitment in turnover intentions: A two-sample study. Journal of Business and Psychology, 22(3), 275-286.

Zellars, K. L., Perrewé, P. L., \& Hochwarter, W. A. (2000), Burn-out in healthcare: The role of the five factors of personality. Journal of Applied Social Psychology, 30, 1570-1598.

Zhao, X., Lynch, J. G., \& Chen, Q. (2010). Reconsidering Baron and Kenny: Myths and truths about mediation analysis. Journal of consumer research, 37(2), 197-206. 